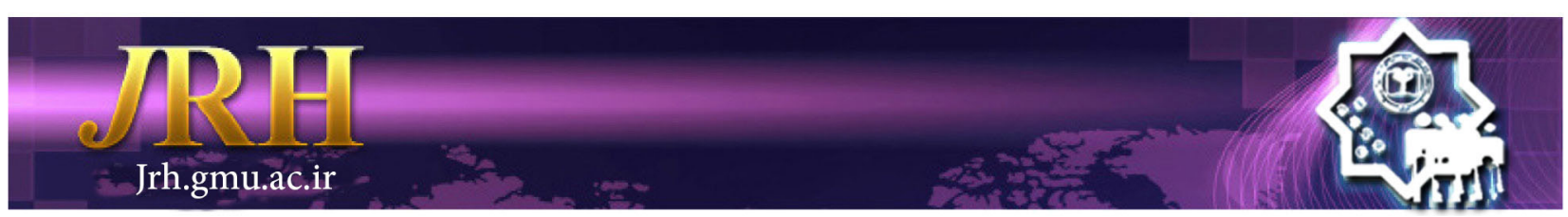

\title{
The effect of social media quality and social presence on intention towards social commerce with the emphasis on educational services
}

Maryam Soleimani ${ }^{1}$

\author{
Journal of Research \& Health \\ Social Development \& Health Promotion \\ Research Center \\ Vol. 9, No. 5, Sep \& Oct 2019 \\ Pages: $454-462$ \\ DOI: 10.29252 /jrh.9.5.454 \\ Original Article
}

1. Correspondence to: Department of Management, Economics and Accounting, Payame Noor University, Tehran, Iran

Email: m.soleimani@pnu.ac.ir

Received: 30 May 2017

Accepted: 23 Apr 2018

How to cite this article: Soleimani M. The effect of social media quality and social presence on intention towards social commerce with the emphasis on educational services. $\mathrm{J}$ Research \& Health2019; 9(5): 454- 462.

\begin{abstract}
Today, social media as a channel for offering educational services has become an extensive and effective educational tool for the students. This survey aimed to investigate the effective factors on intention towards social commerce of educational services among students. The statistical population included social media users at Isfahan university of medical sciences in Iran. 214 students were selected as the research sample by simple random sampling method. The conceptual model was adopted from theoretical literature and empirical studies. Research findings disclosed that social media quality and social presence have a positive and significant effect on intention towards social commerce. Moreover, social media quality has a negative significant effect on students' perceived risk. Similarly, perceived risk has a negative significant effect on students' intention towards social commerce and it showed a partial mediating effect in the relationship between social media quality and intention towards social commerce. The results revealed that higher quality of social media as well as social presence in social media increases tendency of students at Isfahan university of medical sciences to participate in social commerce of educational services and decreases their perceived risk. Therefore, it can encourage students to utilize the presented educational services in social media.
\end{abstract}

Keywords: Commerce, Educational Services, Social Presence

\section{Introduction}

Considerable advances in the Internet environment include Web 2 technology which has provided amazing opportunities to develop ways of interaction with consumers in a virtual environment. In particular, Web 2 applications have made it possible for people to create and maintain their online social networks [1]. Via this technology, social media has been developed as a mechanism to exchange knowledge and information with local, national and global communities [2]. Definitely, tools and applications of social media have challenged the concept of common formal education through the current method. Receiving educational services by means of social media contains the implication which learners should become active producers of knowledge rather than passive consumers of content [3]. Therefore, social media can successfully be used to support "student-centered learning" [4]. Social commerce is a subset of e-commerce [5] that has been appeared via the popularity of social 
media [6]. In social commerce, people can have access to their intended products and services such as educational services through social media. The most important characteristic of social commerce is that consumers can interact in this environment and support each other in the shopping process in terms of providing experiences and information [7]. Different technological and social characteristics in social commerce can affect users' participation. One of these characteristics is social media quality. Users' issues with regard to purchasing activities can be solved due to the appropriate quality of social media and their expectations will be satisfied well. This will be led to customers' intention to participate in social commerce. Social media quality is positively effective on customers' perception and thus, their social shopping is influenced [8]. Employing a highquality medium will convince the users that it is an appropriate tool for social and commercial interactions. In this way, the users can share their experiences. Hence, Social Commerce Intention (SCI) has been influenced positively and significantly by social media quality. The effect of social media quality including web design and content, system quality, information quality, and service quality on success of electronic commerce [9-15] as well as social commerce $[16,8]$ has been emphasized in previous studies. Customers may have intention to divulge their own information in the event that they trust in authenticity of a website. This will reduce anxiety of the customers about security and privacy issues [17]. Thus, customer's perceived risk will be decreased. The effect of system quality including the information that is provided by a website on trust formation in online shopping has been emphasized in several studies [18]. Customers will purchase with more certainty and will perceive a lower risk if they have confidence in social media quality.

Social presence is another important factor in social commerce. It refers to the extent that people who interact in media have a sense of being together [19]. Previous studies have emphasized the importance of social presence in trust building $[20,21]$ and tendency to participate in online recommendation system [21]. Social presence is central element in social content that is defined as sense of consciousness of a person about the presence of another party in the interaction. Social media that is more interactive and can convey more types of information is more appropriate to decrease ambiguity in relations [22]. Social presence in media has a positive and significant relationship with users' trust in that media [20,23]. It can be effective on customer's sense of comfort and creates psychological proximity in an individual. In social commerce, customers who experience social presence via warm and personal social interactions can have a higher sense of comfort and experience customer satisfaction [24]. Therefore, it can be stated that social presence is probably effective on customers' tendency towards online social commerce.

Also, it has been shown that customers perceived a higher risk in an online environment than a traditional environment $[25,26]$. Perceived risk is effective on attitude [27] and loyalty [28] of the virtual user and therefore, it plays a vital role in online shopping [29]. Negative effect of perceived risk on online shopping behaviors has been confirmed in some studies [29]. Hence, perceived risk is one of the determining factors in social commerce. According to the results of previous studies, perceived risk decreases customer's intention towards online shopping [27]. Interactions among the people in social commerce have become possible via social media. Cultures, beliefs and experiences of others are probably effective on the customer's behavior [30]. Consequently, perceived risk in social commerce can be more challenging for customers in return for e-commerce [7].

Words such as Knowledge 2, Health 2 and Medicine 2 which have been inspired by the concept of web 2 can imply changing the way of doing things in an opener and more participatory form [31]. Social media tools have gradually become common in education and have created value in the learning process [32]. Today, many health-related educational and professional services such as academic conferences and 
professional meetings are provided through social media. Thus, these digital learning environments can enhance learning experiences of educators in the field of medical sciences [2,33] and deepen their participation and cooperation at the international level [34]. Social media, thus, has become a useful tool in academic environment [32] through which medical sciences students can have access to health-related educational services. However, the use of social media with the purpose of enjoying educational services is in its primary stages and potential capacity of media particularly in the field of education has been ignored. Undoubtedly, customer participation in social media is a determining factor in success of businesses [35] and education activists who seek economic value from social commerce. As a great volume of health-related content, information and educational services is presented through social media, exploring the stimulating and inhibiting factors of participation in social commerce and educational services is important. Identification of these factors can be important for active businesses in the field of social commerce of educational services. In addition, the effective factors on tendency of medical sciences students toward the use of social media to achieve educational services are identified. As a result, it will help the activists propose more effective educational programs that encourage virtual learning in social media.

The present survey aims to explore the effective factors on intention towards social commerce in medical education services. Therefore, it would explore how social media quality and social presence influence the intention towards social commerce of educational services for medical sciences students through the variable of perceived risk.

\section{Method}

This survey was conducted in March 2016. The statistical population was consisted of social media users at Isfahan University of Medical Sciences in Iran. The sample size was 212 by Sample Power software 3.0.1 with considering the confidence level $95 \%$, statistical power $80 \%$ and the effect size 5\%. 240 questionnaires were distributed among the users both in online (by email) and written forms. Among 230 returned questionnaires, 214 questionnaires contained valid responses and the remaining ones were omitted. The participants included midwifery, nursing, health, dentistry and medical students selected by simple random sampling method from undergraduate, postgraduate and PHD students. Conceptual model of the survey includes four constructs: social media quality and social presence as the independent variables, perceived risk as the mediating variable, and SCI as the dependent variable. In order to improve validity and reliability, the items were extracted from related literature. The questions were developed according to the Likert five-option scale ( $1=$ strongly disagree to $5=$ strongly agree). Social media quality in the present survey is a construct consists of ease of use, transactional safety and reputation of social media. Social presence measures perceived warmth, conveying a feeling of human contact, sociability and sensitivity within social media. SCI measures the desire to participate in online shopping, educational services through social media and perceived risk is composed of dimensions of psychological risk, time at risk, privacy risk and product risk. The hypotheses are formulated as follows:

$\mathrm{H} 1$ : Social media quality has negative effect on perceived risk.

$\mathrm{H} 2$ : Social media quality has positive effect on user's SCI.

H3: Social presence has negative effect on perceived risk.

H4: Social presence has positive effect on user's SCI.

H5: Perceived risk has negative effect on user's SCI.

In this section, Structural Equation Modeling (SEM) was employed. This method is highly used in studying social sciences because of its capability in evaluating the theoretical model [18]. Partial Least Squares (PLS) approach was used for data analysis. It is the most common approach to study information systems [6] and has more advantages than other methods. This approach is appropriate 
for the analysis of small and medium samples. In addition, the condition for data normality in this method is not necessary and it can be utilized in both exploratory and confirmatory studies. Since social commerce is a new phenomenon in e-commerce and nature of the survey is mainly exploratory, PLS is an appropriate approach.

Descriptive analysis of research data using SPSS 23 and conceptual model analysis were performed using PLS 3.0. Convergent validity of the research variables using AVE criterion and factor loadings and divergent validity were analyzed using criterion of FornellLarcker. Variables reliability was measured using Cronbach's alpha coefficient and Composite Reliability. The significance of the path coefficients was investigated to test the research hypotheses at the confidence level of $99 \%$ in structural model. The $\mathrm{R}^{2}$ values were used for investigating the explanatory power of conceptual model. Finally, the mediating effect of perceived risk variable was analyzed by examining the total, direct and indirect effects of the independent variables on the dependent at the confidence level of $99 \%$.

\section{Results}

In PLS, reliability or internal consistency is measured through Composite Reliability (CR) and Cronbach's alpha coefficient. Value of the two measures should be more than 0.7 [37]. Values of these measures in Table 1 show a high internal consistency and the desired reliability.

In PLS, validity is measured by using two measures of convergent validity and divergent validity. Convergent validity indicates the extent to which items measure a construct. It is measured using Average Variance Extracted (AVE) criterion at the construct level. This criterion shows how much a set of items in a latent variable correlate together [36]. The cutoff point for this criterion is equal to 0.5 [38].

Table 1 Indicator loadings and Cronbach's alpha coefficients of constructs

\begin{tabular}{|c|c|c|c|c|c|}
\hline Constructs & Indicators & Loadings & $\mathrm{CR}$ & AVE & Cronbach's $\alpha$ \\
\hline \multirow{8}{*}{ Social Media Quality } & Ease1 & 0.537 & \multirow{8}{*}{0.921} & \multirow{8}{*}{0.600} & \multirow{8}{*}{0.900} \\
\hline & Ease2 & 0.561 & & & \\
\hline & TS1 & 0.827 & & & \\
\hline & $\mathrm{TS} 2$ & 0.824 & & & \\
\hline & TS3 & 0.839 & & & \\
\hline & Rep1 & 0.860 & & & \\
\hline & Rep2 & 0.856 & & & \\
\hline & Rep3 & 0.809 & & & \\
\hline \multirow{3}{*}{ Social Presence } & SP1 & 0.818 & \multirow{3}{*}{0.900} & \multirow{3}{*}{0.750} & \multirow{3}{*}{0.838} \\
\hline & SP2 & 0.871 & & & \\
\hline & $\mathrm{SP} 3$ & 0.906 & & & \\
\hline \multirow{8}{*}{ Perceived Risk } & PR1 & 0.643 & \multirow{8}{*}{0.899} & \multirow{8}{*}{0.528} & \multirow{8}{*}{0.871} \\
\hline & PR2 & 0.788 & & & \\
\hline & PR3 & 0.811 & & & \\
\hline & PR4 & 0.772 & & & \\
\hline & PR5 & 0.736 & & & \\
\hline & PR6 & 0.708 & & & \\
\hline & PR7 & 0.677 & & & \\
\hline & PR8 & 0.660 & & & \\
\hline \multirow{4}{*}{$\begin{array}{l}\text { Intention towards social } \\
\text { commerce }\end{array}$} & SCI1 & 0.820 & \multirow{4}{*}{0.901} & \multirow{4}{*}{0.694} & \multirow{4}{*}{0.853} \\
\hline & $\mathrm{SCI} 2$ & 0.874 & & & \\
\hline & $\mathrm{SCI} 3$ & 0.828 & & & \\
\hline & SCI4 & 0.809 & & & \\
\hline
\end{tabular}

Notes: $\mathrm{SMQ}=$ Social Media Quality $($ Ease $=$ Ease of use, $\mathrm{TS}=$ Transactional Safety, Rep $=$ Reputation), PR $=$ Perceived Risk, $\mathrm{SCI}=$ Intention towards Social Commerce, $\mathrm{SP}=$ Social Presence. 
According to Table 1, AVE of all constructs is more than 0.5 ; thus, they have convergent validity. Discriminant validity indicates the extent to which a certain construct is different from other constructs. It is measured by means of criterion of Fornell-Larcker at the construct level [33]. According to the results (Table 2), all constructs have discriminant validity.

The second way to measure convergent validity and discriminant validity is to explore values of factor loadings for each index. To achieve convergent validity, factor loadings should be positive and at least greater than 0.4 . In order to realize discriminant validity at the indicator level, factor loading of each index on its own construct should be greater than factor loadings on other constructs [38]. According to the results, convergent validity and discriminant validity have been realized at the indicators' level.

Table 2 Results of Discriminant validity test

\begin{tabular}{lcccc}
\hline & $\begin{array}{c}\text { Intention towards } \\
\text { Social Commerce }\end{array}$ & Social Presence & $\begin{array}{c}\text { Perceived } \\
\text { Risk }\end{array}$ & $\begin{array}{c}\text { Social Media } \\
\text { Quality }\end{array}$ \\
\hline Intention towards Social Commerce & 0.833 & & & \\
Social Presence & 0.441 & 0.866 & & \\
Perceived Risk & -0.420 & -0.182 & 0.727 & \\
Social Media Quality & 0.567 & 0.437 & -0.465 & 0.774 \\
\hline
\end{tabular}

Notes: Off-diagonal elements show inter-correlations between the constructs, while diagonal elements in bold and italic are square roots of AVE for each construct.

The acceptable responses included $29.9 \%$ male and $70.1 \%$ female respondents; $43 \%$ were between 20-30 years old and in terms of the educational level, $85 \%$ of them were undergraduate ones. Moreover, $30.8 \%$ of the respondents experience five more times shopping from social media.

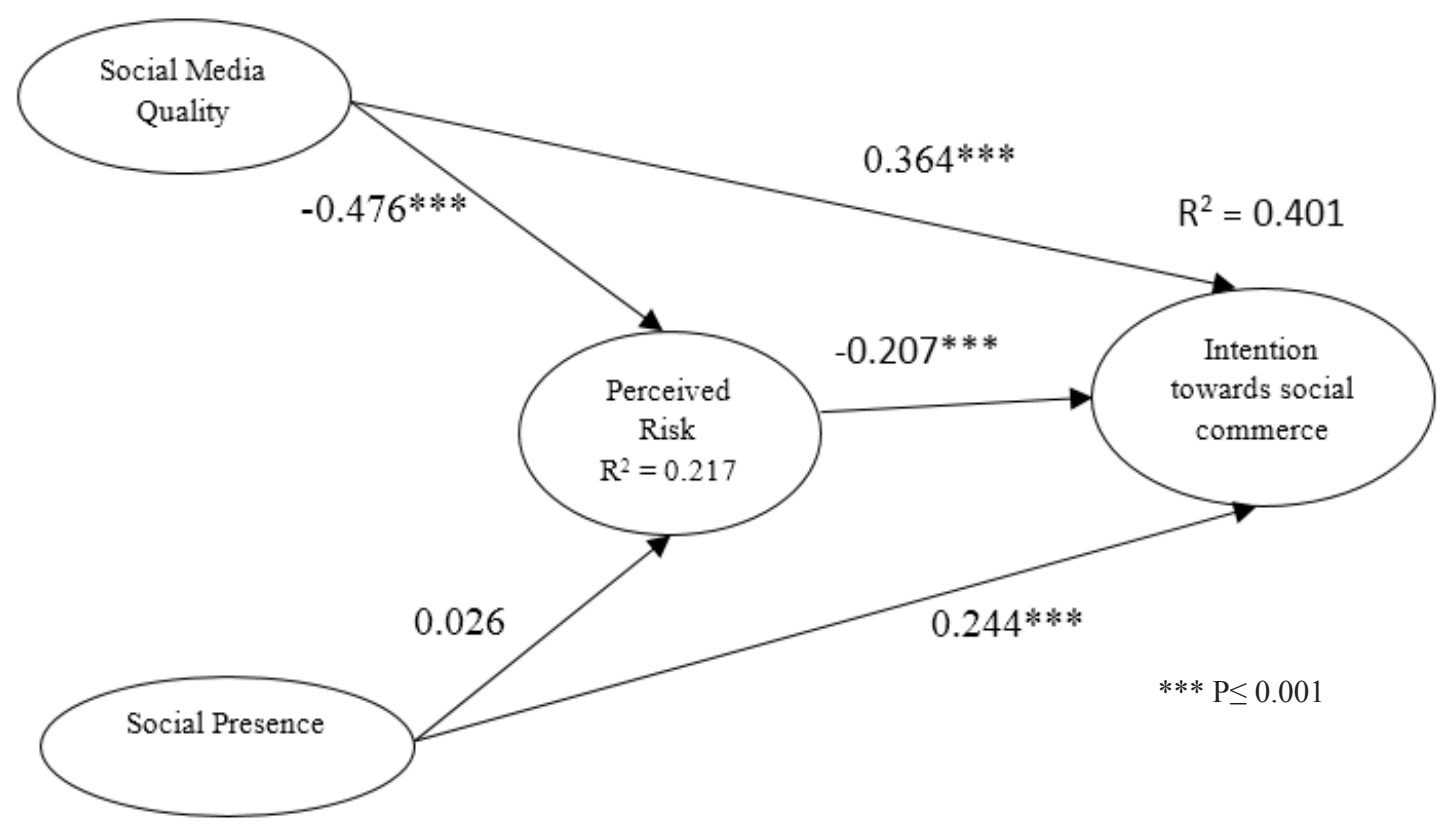

Figure 1 Results of the PLS analysis

The results are displayed in Figure 1 and Table 3. According to the results, social media quality and social presence with path coefficients equal to 0.364 and 0.244 at the confidence level $99 \%$ have a positive significant effect on Social
Commerce Intention (SCI). Consequently, social media quality has a stronger effect on SCI than social presence. Path coefficients for the effect of social media quality and social presence on perceived risk show social media 
quality with path coefficient equal to -0.476 has a negative significant effect on perceived risk but the effect of social presence on perceived risk is not significant.

Explanatory power of the model can be examined using $\mathrm{R}^{2}$ values. $\mathrm{R}^{2}$ was estimated equal to 0.401 for Social Commerce Intention (SCI) and 0.217 for perceived risk. These values show $40.1 \%$ of variance for SCI is explained by constructs of social media quality, social presence and perceived risk and $21.7 \%$ of variance for perceived risk is explained by social media quality and social presence. Value of $\mathrm{R}^{2}$ represents explanatory power of the model.

Table 3 Results of testing the hypotheses

\begin{tabular}{lcccc}
\hline Hypotheses & Structural path & Path coefficients & T Statistics & Supported \\
\hline H1 & SMQ - > PR & $-0.476^{* * *}$ & 8.053 & Yes \\
H2 & SMQ - > SCI & $0.364^{* * *}$ & 5.326 & Yes \\
H3 & SP - > PR & 0.026 & 0.361 & No \\
H4 & SP - > SCI & $0.244^{* * *}$ & 4.090 & Yes \\
H5 & PR - > SCI & $-0.207^{* * *}$ & 3.401 & Yes \\
\hline
\end{tabular}

Notes: $\mathrm{SMQ}=$ Social Media Quality, PR = Perceived Risk, SCI = Intention towards Social commerce, $\mathrm{SP}=$ Social Presence. $* * * \mathrm{p} \leq 0.001$

The mediating effect of perceived risk between social media quality and social presence was explored by Social Commerce Intention (SCI). According to the results in Table 4, given that total effect, direct effect and indirect effect of social media quality on Social Commerce Intention (SCI) is significant so it can be concluded that perceived risk plays partial mediating role in the relationship between social media quality and Social Commerce Intention (SCI). Because the direct effect of social presence on Social Commerce Intention (SCI) is significant and its indirect effect is not significant, the effect of social presence on SCI is explored directly and without perceived risk variable.

Table 4 Testing the mediating effects.

\begin{tabular}{lccccc}
\hline \multirow{2}{*}{ IV } & \multirow{2}{*}{ DV } & \multicolumn{4}{c}{ Effect type } \\
\cline { 3 - 6 } & & Total & Direct & Indirect & Mediating effect \\
\hline SMQ & \multirow{2}{*}{ SCI } & $0.462^{* * *}$ & $0.364^{* * *}$ & $0.098^{* *}$ & Partial \\
SP & & $0.239^{* * *}$ & $0.244^{* * *}$ & -0.005 & No Mediating effect \\
\hline *** $\mathrm{p} \leq 0.001,{ }^{* *} \mathrm{p} \leq 0.01$ & & & &
\end{tabular}

\section{Discussion}

If social media is used effectively so it can enhance learning experiences of clinical professionals and deepens participation and cooperation of the students in digital learning environments. Deeper involvement in learning elements and online discussion groups has significant benefits to develop professional activities [34]. Social media technologies can strengthen and improve the efforts of traditional medical education and also can prepare the students for the future where social media plays important role in medical sciences [32]. The aim of this study was to investigate the effect of social media quality and social presence on intention towards social commerce of educational services at Isfahan University of Medical Sciences. Based on this study's results, social media quality has a positive effect on intention towards social commerce of educational services and it reduces perceived risk of students. Similarly, social presence has positive effect on intention towards social commerce of educational services but it has not been effective on reduction of perceived risk of medical sciences students. According to the results, perceived risk decreases intention towards social commerce of educational services. 
Exploring the results related to the mediating role of perceived risk revealed that this factor plays partial mediating role in the relationship between social media quality and intention towards social commerce; but this is not true about the relationship between social presence and intention towards social commerce.

The results in this research contain valuable and practical points for businesses in the field of educational services especially medical sciences education as well as education planners and activists. First, the results revealed that social media quality can play an important role in facilitation of social commerce. In other words, social media quality can improve students' participation in social commerce of educational services. Previous studies on social commerce [8,38] and e-commerce [9-11] would confirm this finding. Thus, high quality of social media facilitates virtual interactions and encourages social commerce. In general, customers perceive more risk in social media. This is particularly more critical in communities where the use of social media is still in its primary stages. Virtual environment users experience less anxiety in high quality social media; therefore, they perceive lower risk in social media activities and as a result, they will have more tendencies to receive educational services through social media. Enhancement of social media quality, therefore, is highly important for the success of social commerce of educational services including medical education.

Another result of this research showed that social presence that is one of the unique characteristics of social media plays significant role in facilitation of social commerce of educational services. In fact, the possibility to perform social interactions in social media and sense of closeness and being together in this environment can have a positive effect on intention towards social commerce. Whatever social media facilitates human relations and users' interaction, they feel more social presence and as a result, they will be encouraged to participate more in social commerce of educational services. The positive effect of social presence on reuse of the online recommendation system by customers [21], trust [20,21,23] and intention towards social commerce [24] has been confirmed in previous studies. Based on the results, social presence cannot decrease perceived risk of users. Seemingly, this is due to the fact that social commerce in Iran especially in the field of educational services is an emerging trend. Although the number of social media users in Iran has dramatically been increased in recent years, the users' perceived risk to perform business activities in social media is very high because of the novelty of this phenomenon. As a result, human emotions that are created via communications among the users cannot decrease their perceptions of the existing risks in business activities.

Another result showed that perceived risk can decrease intention towards social commerce. Accordingly, whatever users perceive more risk in commercial use of social media; they will refrain from receiving and sharing business information with other virtual users. Customers' perceived risk is more important in communities where the use of social media with business purposes is less common. Thus, considering mechanisms to decrease users' risk and social commerce success is very important especially in communities where this process is still in its early stages. The negative effect of perceived risk on customer perceptions and online shopping behavior has been confirmed in previous studies [27].

The present survey had some limitations. The most important limitation was that access to use some social media is prohibited in Iran and this is an underlying problem in social commerce of educational services. Another limitation was the use of field study, because responses of some users may not be compatible with the ones in real world. Considering just one of the social factors associated with social commerce and some components which indicate social media quality was another limitation.

\section{Conclusion}

In general, the results of the study indicated 
higher students' tendency of Isfahan University of Medical Sciences towards social commerce to use the offered educational services in high quality social media. Besides, the users interact easily and there is an intimate and friendly atmosphere between them. On the other hand, whatever students perceive fewer risk to use educational services in social media, they will have more tendency to participate in social commerce. Thus, educational service providers in social media should consider mechanisms to decrease risk of activity in the media. According to the obtained results, enhanced quality of social media in terms of transaction security, ease of use, and reputation can also decrease perceived risk of users.

The current study can provide a better understanding about students' commercial behavior in using medical education services through social media by emphasizing the importance of social media quality and social presence in intention towards social commerce as well as highlighting the importance of perceived risk in social commerce of educational services. The results of present study are highly important particularly for communities in which social commerce is an emerging trend. In future research, it is appropriate to address other social factors such as social support as well as the most important technological factors in social commerce. Likewise, considering the trust factor can be helpful in analyzing the effect of quality of positive perceptions of social media users on tendency to perform social commerce.

\section{Acknowledgments}

The author appreciates the students of Isfahan university of medical sciences.

\section{Authors' contributions}

Study Design: MS

Data collection and analysis: MS

Manuscript preparation: MS

All authors have read and approved the final version.

\section{Conflict of Interest}

"The authors declare that they have no competing interests."

\section{Funding}

The author received no financial support for the research, authorship and/or publication of this article.

\section{Availability of data and materials}

The datasets used and/or analyzed during this study are available from the corresponding author on reasonable request.

\section{References}

1- Hajli N, Shanmugam M, Powell P, Love PE. A study on the continuance participation in on-line communities with social commerce perspective. Technol Forecast Soc2015; 96: 232-41.

2- Schmitt TL, Sims-Giddens SS, Booth RG. Social media use in nursing education. Online $\mathrm{J}$ Issues Nurs2012; 17(3): 2 .

3- Selwyn N. Social media in higher education. World Learn (Lond)2012; 1: 1-10.

4- Goodyear P, Ellis R. University students' approaches to learning: rethinking the place of technology. Distance Educ2008; 29(2): 141-52.

5- Zhou L, Zhang P, Zimmermann H-D. Social commerce research: An integrated view. Electron Commer Res Appl2013; 12(2): 61-8.

6- Hajli MN. The role of social support on relationship quality and social commerce. Technol Forecast Soc Change 2014; 87: 17-27.

7- Featherman MS, Hajli N. Self-service technologies and e-services risks in social commerce era. $J$ Bus Ethics2016; 139(2): 251-69.

8- Liang T-P, Ho Y-T, Li Y-W, Turban E. What drives social commerce: The role of social support and relationship quality. Int $J$ Electronic Commer2011; 16(2): 69-90.

9- Liu C, Arnett KP. Exploring the factors associated with Web site success in the context of electronic commerce. Information \& Management2000; 38(1): 23-33.

10- Susser B, Ariga T. Teaching e-commerce Web page evaluation and design: a pilot study using tourism destination sites. Comput Educ2006; 47(4): 399-413.

11- Ahn T, Ryu S, Han I. The impact of Web quality and playfulness on user acceptance of online retailing. Information \& Management2007; 44(3): 263-75.

12- Shih H-P. An empirical study on predicting user acceptance of e-shopping on the Web. Information \& Management2004; 41(3): 351-68.

13- Rodgers W, Negash S, Suk K. The moderating effect 
of online experience on the antecedents and consequences of online satisfaction. Psychol Mark2005; 22(4): 313-31.

14- Yoon SJ. The antecedents and consequences of trust in online purchase decisions. J Interact Mark 2002; 16(2): 47-63.

15- Chen Y-H, Hsu I-C, Lin C-C. Website attributes that increase consumer purchase intention: A conjoint analysis. J Bus Res2010; 63(9-10): 1007-14.

16- Gatautis R, Medziausiene A. Factors affecting social commerce acceptance in Lithuania. Procedia Soc Behav Sci2014; 110: 1235-42.

17- Chen YH, Barnes S. Initial trust and online buyer behaviour. Data Min Big Data2007; 107(1): 21-36.

18- Kim S, Park H. Effects of various characteristics of social commerce (s-commerce) on consumers' trust and trust performance. Int J Inf Manage2013; 33(2): 318-32.

19- Shin D-H. Defining sociability and social presence in Social TV. Comput Human Behav2013; 29(3): 939-47.

20- Gefen D, Straub DW. Consumer trust in B2C e-Commerce and the importance of social presence: experiments in e-Products and e-Services. Omega2004; 32(6): 407-24.

21- Choi J, Lee HJ, Kim YC. The influence of social presence on customer intention to reuse online recommender systems: the roles of personalization and product type. Int J Electronic Commer2011; 16(1): 12954.

22- Weisberg J, Te'eni D, Arman L. Past purchase and intention to purchase in e-commerce: The mediation of social presence and trust. Internet Res2011; 21(1): 82-96. 23- Ogonowski A, Montandon A, Botha E, Reyneke M. Should new online stores invest in social presence elements? The effect of social presence on initial trust formation. J Retail Consum Serv2014; 21(4): 482-91.

24- Zhang H, Lu Y, Gupta S, Zhao L. What motivates customers to participate in social commerce? The impact of technological environments and virtual customer experiences. Inf Manag2014; 51(8): 1017-30.

25- Wang Y-S, Wang Y-M, Lin H-H, Tang T-I. Determinants of user acceptance of Internet banking: an empirical study. International Journal of Service Industry Management 2003;14(5):501-19.

26- Mukherjee A, Nath P. A model of trust in online relationship banking. International Journal of Bank Marketing2003;21(1):5-15.

27- Chang Lee K, Curras-Perez R, Ruiz-Mafe C, SanzBlas S. Social network loyalty: evaluating the role of attitude, perceived risk and satisfaction. Online
Information Review2013; 37(1): 61-82.

28- Flavián C, Guinalíu M, Gurrea R. The role played by perceived usability, satisfaction and consumer trust on website loyalty. Information \& Management 2006 ; 43(1): 1-14.

29- McKnight DH, Choudhury V, Kacmar C. The impact of initial consumer trust on intentions to transact with a web site: a trust builsding model. The Journal of Strategic Information Systems2002;11(3-4):297-323. 30- Herrero Á, San Martín H. Explaining the adoption of social networks sites for sharing user-generated content: A revision of the UTAUT2. Comput Human Behav2017; 71: 209-17.

31- Paton C, Bamidis P, Eysenbach G, Margaret M, Cabrer M. Experience in the use of social media in medical and health education. Contribution of the IMIA Social Media Working Group. Yearb Med Inform2011; 20(1): 21-9.

32- George DR, Dellasega C. Use of social media in graduate-level medical humanities education: two pilot studies from Penn State College of Medicine. Med Teach2011; 33(8): e429-e34.

33- Thames G. Twitter as an educational tool. J Child Adolesc Psychiatr Nurs2009; 22(4): 235.

34- Boulos MNK, Maramba I, Wheeler S. Wikis, blogs and podcasts: a new generation of Web-based tools for virtual collaborative clinical practice and education. BMC Med Educ2006; 6(1): 1-8.

35- Wang C, Zhang P. The evolution of social commerce: The people, management, technology, and information dimensions. Communications of the Association for Information Systems2012; 31(5): 105-127.

36- Delone WH, McLean ER. The DeLone and McLean model of information systems success: a ten-year update. J Manag Inf Syst2003; 19(4): 9-30.

37- Chin WW. How to Write Up and Report PLS Analyses. In: Esposito Vinzi V, Chin WW, Henseler J, Wang H, eds. Handbook of Partial Least Squares: Concepts, Methods and Applications. Berlin Heidelberg: Springer; 2010. pp: 655-90.

38- Hasan L, Abuelrub E. Assessing the quality of web sites. Applied Computing and Informatics2011; 9(1): 11-29.

39- Lee D, Yejean Park J, Kim J, Kim J, Moon J. Understanding music sharing behaviour on social network services. Online Information Review2011; 35(5): 716-33.

\footnotetext{
Copyright $(\mathrm{C} 2016$ ASP Ins. This open-access article is published under the terms of the Creative Commons Attribution-NonCommercial 4.0 International License which permits Share (copy and redistribute the material in any medium or format) and Adapt (remix, transform, and build upon the material) under the Attribution-NonCommercial terms.
} 